\title{
IN VITRO STUDIES OF INTERACTION BETWEEN METFORMIN AND NSAIDS (NON STEROIDAL ANTI- INFLAMATORY DRUGS) USING SPECTROPHOTOMETRY AND RP-HIGH PERFORMANCE LIQUID CHROMATOGRAPHY
}

\author{
M. SAEED ARAYNEI , NAJMA SULTANA', M. HASHIM ZUBERI AND UROOJ HAROON ${ }^{1,3}$ \\ 1Department of Chemistry, University of Karachi, Karachi 75270, Pakistan \\ 2Department of Pharmaceutical Chemistry, Faculty of Pharmacy, University of Karachi, Karachi 75270, Pakistan \\ 3Department of Chemistry, Federal Urdu Science University for Arts, Science and Technology, Karachi 75300, Pakistan
}

(Received: July 20, 2009 - Accepted: November 2, 2009)

\begin{abstract}
Patients diagnosed with diabetes are prescribed a large number of medications for appropriate therapy, increasing risk of side effects or drug interactions. Metformin, a guanidine derivative is commonly used as a drug of choice for the treatment of non insulin dependent diabetes mellitus. There are a number of interactions reported for metformin. On the other hand, NSAIDs are generally used for the treatment of pain, fever and inflammation, particularly arthritis. Since the former drug is used in long term therapy, it may be co-administered with other drugs. In the present paper, we investigated the in-vitro availability of metformin in presence of commonly used NSAIDs, like diclofenic sodium, flurbiprofen, ibuprofen, mefenamic acid, meloxicam and tiaprofenic acid. These studies were carried out using modified BP 2007 dissolution test apparatus in simulated body environments at $37^{\circ} \mathrm{C}$. These drug interactions were analyzed by UV/ VIS spectroscopy and the effect on the availability of both metformin and NSAIDs in presence of each other was calculated by applying simultaneous equation which was derived by modifying Beers law. The interactions were further studied by RP-HPLC with mobile phase consisting of methanol and water (80:20 $\mathrm{v} / \mathrm{v}$ ) maintained at a flow rate of $1 \mathrm{mLmin}^{-1}$ at isobestic point $241 \mathrm{~nm}$ (metformin, diclofenac sodium, flurbiprofen, tiaprofenic acid, ibuprofen, meloxicam and mefenamic acid) respectively. The results showed that the in vitro availability of NSAIDs and metformin owing to interaction was depressed through the formation of charge transfer complexes which was found to be associated with inter- and intra-molecular rearrangement of the electronic cloud of the interacting drugs. Hence it is envisaged that concurrent administration of metformin and NSAIDs could alter the bio-availability and impair the clinical efficacy of both drugs. Effect of pH is also studied on these drug-drug interactions.
\end{abstract} HPLC,

KeyWords: Metformin, Nsaids, diclofenac sodium, flurbiprofen, ibuprofen, mefenamic acid, meloxicam and tiaprofenic acid, UV spectrophotometry, RP-

\section{INTRODUCTION}

Metformin, N,N-dimethylimidodicarbonimidic diamide hydrochloride is a biguanide, known to posses antihyperglycemic activity. It enhances insulin sensitivity and is not effective in the absence of insulin ${ }^{~}$. It lowers blood glucose level in NIDDM patients by suppressing hepatic glucose output and enhancing peripheral glucose uptake. Use of a biguanide concomitantly with other drugs that lower blood sugar concentrations increases the risk of hypoglycemia, while drugs that increase blood glucose may reduce the effect of biguanide therapy.

Literature survey reveals potential adverse drug interactions with anti-diabetic medicines and cimetidine ${ }^{2,3}$, cetirizine ${ }^{4}$, fexofenadine ${ }^{4}$ and levocetirizine ${ }^{4}$, diclofenac sodium ${ }^{5}$, piroxicam ${ }^{6}$ and indobufen ${ }^{7}$. By considering these studies, it was observed that not much attention was paid to the possible interaction of metformin with NSAIDs or in some cases the reported methods seemed vague. As NSAIDs are widely prescribed in cases of pain and inflammation for this reason, scope of this study was to investigate the possible effect on hypoglycemic patients. From above findings it was understood that there are chances of interaction between metformin and commonly prescribed NSAID's like diclofenac sodium, flurbiprofen, ibuprofen, mefenamic acid, meloxicam and tiaprofenic acid. Simultaneous administration of these drugs may affect the $\%$ availability of each other ${ }^{8}$.

Consequently, the aim of the present work was to find out such interactions of metformin with commonly prescribed, NSAIDs. The interaction studies were carried out in vitro, at physiological temperature $\left(37^{\circ} \mathrm{C}\right)$ in different $\mathrm{pH}$ environments simulating full stomach juice $(\mathrm{pH} 4)$ and intestinal juice ( $\mathrm{pH}$ 6.8-9). In order to simulate peristaltic movements of the stomach, dissolution test apparatus (B.P. 2007) was used. The reactions were studied individually by UV/Visible spectroscopy and RP-HPLC. Although there are several assay methods reported for the analysis of these drugs alone by HPLC 9-41 and UV 16, 36, 42-48 but there is no method reported for the simultaneous determination of metformin and selected NSAIDs in bulk drug and in tablet formulation. Therefore, prior to these interaction studies, it became apparent to develop and validate simultaneous assay method of these drugs by RP-HPLC which was later applied to drug-drug interaction studies of metformin and selected NSAIDs.

\section{EXPERIMENTAL}

\section{Material and Reagents}

Reference standards of metformin and tiaprofenic acid were kindly gifted by Sanofi-aventis Pharma (Pakistan) Ltd., diclofenac sodium from Indus Pharma (Pvt.) Ltd., ibuprofen from Abbott Laboratories (Pakistan) Ltd., flurbiprofen and mefenamic acid from Pfizer Laboratories Pakistan Ltd. and meloxicam from AGP Pakistan (Pvt.) Ltd. Metformin, tiaprofenic acid, diclofenac sodium, ibuprofen, meloxicam, flurbiprofen and mefenamic acid tablets (Neodipar 25mg, Surgum 200mg, Dyclo 50mg, brufen 200mg, Melfax $15 \mathrm{mg}$, Ansid 100mg, Ponstan 200mg) were purchased from local market. HPLC grade methanols (TEDIA ${ }^{\circledR}$, USA), $85 \%$ ortho-phosphoric acid (Merck, Germany), freshly prepared double distilled and deionized water were used in the analysis.

Apparatus

Electrical weighing balance (Mettler Toledo no. AB54), pH meter (Mettler Toledo MP 220), dissolution equipment was manufactured according to the B.P 2007 standards, with slight modifications. Shimadzu UV/visible spectrophotometer model UV1601A coupled with a Pentium IV PC was used for analysis of drug samples, Liquid chromatographic system consisted of Shimadzu model LC-20 AT VP pump, Rheodyne manual injector fitted with a $20 \mu \mathrm{L}$ loop, a Shimadzu model SPD-20AV variable wavelength UV-Visible detector (Shimadzu Corporation, Kyoto, Japan). Chromatographic system was integrated via Shimadzu model CBM-102 Communication Bus Module. Analysis was conducted on a Purospher® STAR HPLC column ( $250 \mathrm{~mm}$ x 4.5 id) analytical reverse phased column, CLASS-GC10 (version 2) and UVPC (version 3.9) used for data acquisition.

\section{UV-Visible spectrophotometry}

\section{Solution preparation}

Buffer preparations

To prepare buffer of $\mathrm{pH}$ 4, $0.1 \mathrm{M}$ potassium chloride solution was prepared and $(0.1 \mathrm{M})$ hydrochloric acid was added until the appropriate $\mathrm{pH}$ was attained. For the preparation of $\mathrm{pH} 6.8$ buffer, potassium dihydrogen orthophosphate $(0.6 \mathrm{~g})$, disodium hydrogen orthophosphate $(6.4 \mathrm{~g})$ and sodium chloride $(5.85$ g) were dissolved in sufficient deionized water to produce $1000 \mathrm{~mL}$ and $\mathrm{pH}$ was adjusted with $17 \%$ ammonium hydroxide. In the same way $\mathrm{pH} 9$ buffer was prepared by dissolving (17.4 g) of potassium dihydrogen orthophosphate 
in $800 \mathrm{~mL}$ of deionized water, and $\mathrm{pH}$ was adjusted with $17 \%$ ammonium hydroxide.

\section{Calibration Curve}

For calibration curve, working standard solutions of metformin and NSAIDs (diclofenac sodium, flurbiprofen, ibuprofen, mefenamic acid, meloxicam and tiaprofenic acid) in concentration ranging from 0.01 to 0.1 mMole were prepared in buffer of $\mathrm{pH} 4$. The absorbance maxima were scanned in the region of $190-700 \mathrm{~nm}$ for these solutions against the reagent blank. Graphs were plotted for absorbance against concentration and straight lines were obtained which obeyed Lambert and Beer's Law. Epsilon values were calculated from these observations. The above procedure was repeated for buffers of $\mathrm{pH} 6.8$ and 9.

\section{In vitro availability studies}

In vitro availability of metformin and NSAIDs in individual dosage formulations were studied separately in different mediums each being $500 \mathrm{~mL}$ of buffers of $\mathrm{pH} 4,6.8$ and 9 on dissolution test apparatus maintained at $37^{\circ} \mathrm{C}$. $5 \mathrm{~mL}$ aliquots were withdrawn with an interval of 15 minutes for 2 hours and volume of dissolution fluid was maintained to $500 \mathrm{~mL}$ by adding an equivalent amount withdrawn, which was previously maintained at the same temperature in the same bath. Each drug was analyzed after making suitable dilution with $80 \%$ methanol for its contents at their absorption maxima on a UV/visible spectrophotometer. Each experiment was performed three times and the results are given as mean \pm standard deviation.

\section{In vitro interaction studies}

In vitro interaction studies of the metformin with NSAIDs were carried out at $37^{\circ} \mathrm{C}$. In each sets of experiments metformin and diclofenic sodium (NSAIDs) was added into the $500 \mathrm{~mL}$ of dissolution medium at zero time. After every 15 minutes time interval $5 \mathrm{~mL}$ aliquots were withdrawn and the above procedure was repeated with flurbiprofen, ibuprofen, mefenamic acid, meloxicam and tiaprofenic acid at same experimental conditions. \% availability of each drug versus time was calculated in each set of experiment. Each experiment was performed three times and the results are given as mean \pm standard deviation.

During the analysis, it was observed that the absorption band of each drug interfered with the other drug. Therefore, simultaneous equation was employed, in order to measure quantities of two drugs present in the same solution.

$$
\begin{array}{ll}
\text { Similarly, } \quad \mathrm{C}_{\mathrm{a}}=\frac{\mathrm{A}_{1} \cdot \mathrm{b}_{2}-\mathrm{A}_{2} \cdot \mathrm{b}_{1}}{\mathrm{a}_{1} \mathrm{~b}_{2}-\mathrm{a}_{2} \mathrm{~b}_{1}} \\
\mathrm{C}_{\mathrm{b}}=\frac{\mathrm{A}_{1} \cdot \mathrm{a}_{2}-\mathrm{A}_{2} \cdot \mathrm{a}_{1}}{\mathrm{a}_{2} \mathrm{~b}_{1}-\mathrm{a}_{1} \mathrm{~b}_{2}}
\end{array}
$$

Where $\mathrm{Ca}$ and $\mathrm{Cb}$ were the concentration of metformin and flurbiprofen (NSAID), $\mathrm{a}_{1}$ and $\mathrm{a}_{2}$ were the molar absorptivites of metfomrin at 233 and 247 $\mathrm{nm}$, while $\mathrm{b}_{1}$ and $\mathrm{b}_{2}$ were the molar absorptivites of flurbiprofen at 233 and 247 $\mathrm{nm}$. This equation holds well when $\lambda_{\max }$ of both the drugs are relatively far apart

\section{HPLC}

\section{Wavelength selection}

In addition, the UV spectra of individual drugs were recorded in the wavelength range from 200 to $400 \mathrm{~nm}$ and compared. The $241 \mathrm{~nm}$ isobestic point was considered satisfactory for all the drugs with adequate sensitivity.

Chromatographic conditions

The mobile phase consisted of methanol-water (80:20) whose pH was adjusted to 3.2 with phosphoric acid (85\%). Prior to delivering into the system it was filtered through $0.45 \mathrm{~mm}$ filter and degassed using an ultrasonic bath. The analysis was carried out under isocratic conditions using a flow rate of 1.0 $\mathrm{mLmin}^{-1}$ at room temperature. The samples were introduced by injector with a 20 -mL sample loop. Chromatograms were recorded at $241 \mathrm{~nm}$ using a detector SPD-20AV Shimadzu UV visible.

\section{Standard solutions}

Stock solutions $50 \mu \mathrm{gmL}^{-1}$ of metformin and $100 \mu \mathrm{gmL}^{-1}$ all NSAIDs (diclofenac sodium, flurbiprofen, ibuprofen, mefenamic acid, meloxicam and tiaprofenic acid) were prepared. The stocks solutions were then sequentially diluted to $2.5-12.5 \mu \mathrm{gmL}^{-1}$ for metformin and $5-25 \mu \mathrm{gmL}^{-1}$ for NSAIDs with $80 \%$ methanol (diluent) working standard solutions for preparation of calibration curves.

\section{Assay for dosage formulation}

To determine the active ingredient of these drugs in dosage formulations, individual tablets (10) were pulverized using a mortar and pestle, and $10 \mathrm{mg}$ of the powdered tablets was transferred in to a $100 \mathrm{~mL}$ conical flask. The volume was adjusted with $80 \%$ methanol and the flask was mechanically shaken for $5 \mathrm{~min}$. Stocks solutions were sequentially diluted to give working solution at concentrations 4,8 and $12 \mu \mathrm{gmL}^{-1}$.for $\mathrm{MfCl}$ and 8,16 and $24 \mu \mathrm{gmL}^{-1}$ for all NSAIDs. The samples were filtered through a $0.45-\mathrm{mm}$ membrane filter, the amount of $\mathrm{MfCl}$ (metformin hydrochloride) and NSAIDs per tablet was calculated from the related linear regression equations

\section{Serum drug analysis}

The serum samples were stored in the freezer at $-14^{\circ} \mathrm{C}$ and allowed to thaw at room temperature before processing. The serum samples were centrifuged at $3000 \mathrm{rpm}$ for $6-7 \mathrm{~min}$. An aliquot $(1.0 \mathrm{~mL})$ was pipetted into a $10 \mathrm{~mL}$ polypropylene test tube and acetonitrile $(2.0 \mathrm{~mL})$ was added. The mixture was vortex mixed briefly, and after standing for $5 \mathrm{~min}$ at room temperature, the mixture was centrifuged at $3000 \mathrm{rpm}$ for $5 \mathrm{~min}$. The supernatant obtained was filtered through a $0.45 \mathrm{~mm}$ filter. Serum thus obtained was mixed in ratio of 1:1 with drug solutions and was then injected into the HPLC system. A spiked serum sample with metformin and NSAIDs in concentration levels ranging from $0.5,1.0$ and $1.5 \mu \mathrm{gmL}^{-1}$ for metformin and $1.5,3$ and $4.5 \mu \mathrm{gmL}^{-1}$ for all Nsaid's were prepared and were chromatographed.

\section{In-vitro interaction studies by RP-HPLC}

In-vitro interaction study by RP-HPLC was performed by preparing 200 $\mu \mathrm{gmL}^{-1}$ stock solutions of each drug from their tablets in buffers of $\mathrm{pH} 4,6.8$ and 9 (as described earlier). Equal volumes $(10 \mathrm{~mL})$ of metformin and the interacting NSAIDs was taken separately into the reaction flasks to produce final concentrations of $100 \mu \mathrm{gmL}^{-1}$ of metformin and the NSAID in each flask. These flasks were kept in a water bath at constant temperature $\left(37^{\circ} \mathrm{C}\right)$ with constant stirring. $2 \mathrm{~mL}$ was drawn from the reaction flask at zero minute and periodically after 15 minutes for two hours. Aliquots withdrawn were diluted to $10 \mu \mathrm{gmL}^{-1}$ with methanol, filtered through a millipore filter $(0.45 \mu \mathrm{m})$ and analyzed by HPLC using their proposed methods. Peak areas were recorded and compared with standard solutions from which degree of interactions were evaluated.

\section{RESULT AND DISSCUSSION}

The proposed HPLC method for the analysis of metformin and NSAIDs (diclofenac sodium, flurbiprofen, mefenamic acid, meloxicam and tiaprofenic acid) was validated by assessing linearity, accuracy, precision, selectivity, limit of detection and quantitation and hence was found free from the interference of excipients and human serum. This method was then applied on in vitro interaction studies of these drugs. In the second part of this study, the possibility of in vitro interaction of metformin with NSAIDs was also determined by UV visible spectroscopic technique using modified dissolution test apparatus ${ }^{49,50}$. For this analysis linearity of all the drugs in different buffer mediums ( $\mathrm{pH} 4$, 6.8 and 9) were run and epsilon values were calculated. These values were later used in Beers equation and derived simultaneous equation to calculate $\%$ availability of the drugs alone and in presence of each other respectively.

\section{Specificity and Robustness}

The proposed HPLC method provides a simple procedure for the simultaneous determination of metformin and NSAIDs in human serum and dosage forms. The mobile phase methanol: water $(80: 20 \mathrm{v} / \mathrm{v}), \mathrm{pH} 3.2$ at flow rate $1.0 \mathrm{mLmin}^{-1}$ was considered optimum and after several trials the chromatographic peaks were well resolved from the parent analyte which clearly indicates the specificity of the method. The retention times for the investigated drugs were metformin $2.32 \mathrm{~min}$., diclofenac sodium $8.3 \mathrm{~min}$, flurbiprofen $5.21 \mathrm{~min}$., ibuprofen $5.41 \mathrm{~min}$., mefenamic acid $14.82 \mathrm{~min}$. meloxicam $8.93 \mathrm{~min}$., and tiaprofenic acid $7.04 \mathrm{~min}$ (Figure 1). This system is quite robust. Purospher ${ }^{\circledR}$ Star RP-18 $(250 \mathrm{~mm} \times 4.6 \mathrm{~mm}$ id $)$ columns is recommended because it demonstrated ruggedness and reproducibility in this assay. Chromatograms of metformin and NSAIDs (diclofenac sodium, flurbiprofen, ibuprofen, mefenamic acid and tiaprofenic acid) in pharmaceutical formulations and in human serum are given in Figure 1 and 2. The optimum wavelength selected for determination of metformin, diclofenac sodium, flurbiprofen, ibuprofen, mefenamic acid, meloxicam and tiaprofenic acid was $241.0 \mathrm{~nm}$, at which much better detector response for each drug

Validation (linearity, accuracy and precision)

The proposed method was validated by assaying five calibration standards and three samples of dosage formulation in triplicate on three separate days ${ }^{51}$. 
Statistical data were obtained through linear regression analysis in bulk drug and in spiked plasma samples. The linearity of the method was confirmed over the concentration range of 2.5-12.5 $\mu \mathrm{gmL}^{-1}$ for metformin and 5-25 $\mu \mathrm{gmL}^{-1}$. A typical calibration curve had the regression equation as shown in table 1 . The absolute $\%$ recovery of metformin and NSAIDs were also determined.

Inter-day and intra-day precision and accuracy (repeatability) was determined by calculating the found concentration and relative standard deviation (RSD) for five determinations at each concentration of three samples of dosage formulation $(50 \%, 100 \%$ and $150 \%)$ and was found to be less than $3 \%$ (Table 2).

\section{Limit of Detection (LOD) \& Limit of Quantitation (LOQ)}

Limits of detection and quantification (LOD and LOQ) were estimated in accordance with the baseline noise. Limit of detection was obtained as the sample concentration that causes a peak three times as high as the baseline noise level, and the Limit of quantitation was calculated as being ten times as high as the baseline noise level ${ }^{51,52}$ as shown in table 1.

\section{Interaction studies by UV spectroscopy}

The availability of all the drugs in individual dosage formulations and in presence of each other was calculated. It was observed that the individual availability of metformin and NSAIDs after $2 \mathrm{hrs}$ was found to be $100 \%$ in all $\mathrm{pH}$ mediums under study. The interaction of metformin with NSAIDs in $\mathrm{pH}$ 4 buffer at $233 \mathrm{~nm}$ showed that availability of metformin was not decreased considerably in presence of interacted NSAIDs i.e., $99.01 \%$ in presence of diclofenac sodium, $95.39 \%$ in presence of ibuprofen and $97.16 \%$ in presence of tiaprofenic acid with the exception of flurbiprofen and meloxicam, in which the availability of metformin declined to $91.41 \%$ and $91.19 \%$ respectively. On the contrary, presence of metformin brought significant decrease in the availability of tiaprofenic acid and flurbiprofen which were only $1.48 \%$ and $28.22 \%$ available. Availability of diclofenac sodium and meloxicam were also decreased but to a lesser extent i.e., $72.38 \%$ and $45.20 \%$ respectively while a trivial change in the availability of ibuprofen was observed such that the drug was almost completely available i.e., $99.12 \%$. The results indicate that the interacting NSAIDs participated in the formation of a charge transfer complex with metformin ${ }^{53,54}$ through the transfer of electrons from the phenyl groups of NSAIDs, first to the imine carbon and then to the imine nitrogen of $\mathrm{C}=\mathrm{N}$ bond of metformin. The complex so formed is stabilized due to extension of conjugation $(\mathrm{C}=\mathrm{C}---\mathrm{C}=\mathrm{N}$. Similar charge transfer complex of diclofenac sodium has been reported with citrizine and the $\mathrm{CT}$ interaction existed between the aromatic moiety of diclofenac sodium and the doubly charged piperazine moiety of citrizine ${ }^{55}$. Further, the molar absorptivities of complexes formed were lower than the parent drugs; hence diminution in availabilities of the drugs was observed. However, the depression in the availability of metformin was lesser as compared to NSAIDs probably because in the complex formed, the chromophoric site of metformin remained intact and in contrast to NSAIDs, the difference in the molar absorptivity of metformin with respect to its complexes was less.

Similarly in pH 6.8 buffer, a small decrease in the availability of metformin was observed in presence of all the NSAIDs i.e., $95.30 \%$ in presence of diclofenac sodium, $97.18 \%$ in presence of ibuprofen, $92.61 \%$ in presence of flurbiprofen, $99.28 \%$ in presence of mefenamic acid, $93.17 \%$ in presence of meloxicam and $97.16 \%$ in presence of tiaprofenic acid while a considerable depression in the availability of mefenamic acid, diclofenac sodium and tiaprofenic acid was observed such that these drugs were $26.20 \%, 36.43 \%$ and $44.37 \%$ available respectively. Availability of meloxicam and flurbiprofen decreased to $61.82 \%$ and $69.01 \%$ respectively in presence of metformin while the availability of ibuprofen in presence of metformin was only slightly affected and reduced to $98.22 \%$.

After 2 hours, in buffer of $\mathrm{pH} 9$ at $233 \mathrm{~nm}$, metformin, ibuprofen and diclofenac sodium, were almost completely available at the end of experiment, $98.14 \%$ of metformin and $96.47 \%$ of diclofenac sodium, $97.58 \%$ metformin and $96.28 \%$ ibuprofen which suggests that metformin in presence of diclofenac sodium and ibuprofen do not undergo any interaction in intestinal environment, whereas the availability of metformin decreased to $91.26 \%$ in presence of flurbiprofen, while the later drug was $98.52 \%$ available. In case of metformin and mefenamic acid, availability of both the drugs decreased to $93.07 \%$ and $77.93 \%$ respectively, in other case, $93.07 \%$ of metformin and $77.92 \%$ of meloxicam were found available at the end of experiment. The most significant decline in availability of metformin was observed in $\mathrm{pH} 9$ with tiaprofenic acid in which $88.86 \%$ of metformin and $32.98 \%$ of tiaprofenic acid were available. (Table 4)

\section{Interaction studies by RP-HPLC}

The interaction studies by RP-HPLC technique demonstrated similar results shown by UV spectroscopic studies. The reduction in the availability of tiaprofenic acid in presence of metformin was most prominent in all $\mathrm{pH}$ mediums whereby the drug was only $3.7,39.5$ and $35.4 \%$ available while metformin was $98.2,97.05$ and $84.5 \%$ available in $\mathrm{pH} 4,6.8$ and 9 respectively. The interaction of flurbiprofen and meloxicam with metformin was most intense in $\mathrm{pH} 4$ leaving the drugs $38.05 \%$ and $42.2 \%$ available while in $\mathrm{pH} 6.8$, mefenamic acid and diclofenac sodium were only 22.5 and $33.2 \%$ available. The availability of metformin in $\mathrm{pH} 4$ in presence of flurbiprofen and meloxicam was 90.08 and $92.7 \%$ while in presence of mefenamic acid and diclofenac sodium in $\mathrm{pH} 6.8$, metformin was 94.9 and $99.1 \%$ available. In $\mathrm{pH} 9$ the availability of metformin in presence of flurbiprofen, mefenamic acid and meloxicam was $90.9,93.5$ and $94.05 \%$ while the corresponding NSAIDs were $97.2,73.5$ and $74.6 \%$ available. No significant interaction of metformin in presence of ibuprofen and diclofenac sodium was observed in $\mathrm{pH}$ 9. (Table 4)

\section{CONCLUSION}

This RP-HPLC method for the simultaneous determination of metformin and NSAIDs has been successfully developed as it was rapid, precise, accurate showing good percent recovery, low cost and least time consuming as well as low LOD and LOQ values showing sensitivity of the method. It was also applied effectively in the study of metformin and NSAID interaction. These interactions were further studies by UV spectroscopic studies. On the basis of in vitro interaction results obtained from HPLC and UV spectrophotometric techniques, it is clearly indicated that metformin interacted with the selected NSAIDs through the formation of charge transfer complexes, which caused a moderate to significant change on the in vitro availability of the drugs except in case of diclofenac sodium and ibuprofen in $\mathrm{pH} 9$, where no prominent change was observed. It is proposed that if metformin and NSAIDs are co-administered, the delivery of the drugs into the circulation may be altered by physicochemical interaction that could occur prior to their absorption. Although this study did not attempt to investigate the in vivo studies, however this method could be successfully applied to the samples of in vivo subjects.

\section{ACKNOWLEDGEMENT}

The authors wish to thank HEC (Higher Education commission) for providing research scholarships to Mr. Muhammad Hashim Zuberi under (Indigenous Ph.D. 5000 Scholarship Program and (IRSIP) International research support initiative program).

Table 1

\begin{tabular}{|c|c|c|c|c|}
\hline \multicolumn{5}{|c|}{ Regression statistics in bulk drug } \\
\hline Drugs & Regression equation & $\mathrm{R}^{2}$ & $\begin{array}{c}\text { LOD } \\
\left(\mu \mathrm{gmL}^{-1}\right)\end{array}$ & $\begin{array}{c}\text { LOQ } \\
\left(\mu \mathrm{gmL}^{-1}\right)\end{array}$ \\
\hline Metformin & $122386 \mathrm{x}+2942.1$ & 0.9999 & 0.032 & 0.097 \\
\hline Ibuprofen & $40937 \mathrm{x}+820.46$ & 0.9999 & 0.017 & 0.051 \\
\hline Flurbiprofen & $51039 \mathrm{x}-1025.3$ & 0.9989 & 0.013 & 0.041 \\
\hline Tiaprofenic acid & $152810 \mathrm{x}+10885$ & 0.9999 & 0.022 & 0.065 \\
\hline $\begin{array}{c}\text { Diclofenac } \\
\text { sodium }\end{array}$ & $431461 \mathrm{x}+3634.4$ & 0.9999 & 0.015 & 0.047 \\
\hline Mefenamic acid & $151528 \mathrm{x}-9520.9$ & 0.9999 & 0.015 & 0.046 \\
\hline Meloxicam & $182113 \mathrm{x}-2934.8$ & 0.9999 & 0.033 & 0.098 \\
\hline \multicolumn{2}{|c|}{ Regression statistics in presence of human serum } \\
\hline Metformin & $265784 \mathrm{x}+3171.8$ & 0.9961 & 1.01 & 3.06 \\
\hline Ibuprofen & $89124 \mathrm{x}+18397$ & 0.9997 & 0.116 & 0.35 \\
\hline Flurbiprofen & $47308 \mathrm{x}+10033$ & 0.9984 & 0.56 & 1.72 \\
\hline Tiaprofenic acid & $78776 \mathrm{x}-22709$ & 0.9988 & 0.47 & 1.44 \\
\hline $\begin{array}{c}\text { Diclofenac } \\
\text { sodium }\end{array}$ & $79881 \mathrm{x}+1950$ & 0.9998 & 0.86 & 2.61 \\
\hline Mefenamic acid & $14758 \mathrm{x}+3882.7$ & 0.9997 & 0.125 & 0.37 \\
\hline Meloxicam & $4894.6 \mathrm{x}-677.56$ & 0.9995 & 1.39 & 4.21 \\
\hline
\end{tabular}




\begin{tabular}{|c|c|c|c|c|}
\hline \multicolumn{5}{|l|}{ Table 2} \\
\hline \multicolumn{5}{|c|}{ Accuracy and precision of the proposed method in dosage formulations } \\
\hline $\begin{array}{c}\text { Drug } \\
\text { added }\end{array}$ & \multicolumn{3}{|c|}{ Found concentration $\left(\mu \mathrm{gmL}^{-1}\right)$} & \multirow{2}{*}{$\begin{array}{c}\% \text { recovery } \\
\quad( \pm \text { S.D. })\end{array}$} \\
\hline$\left(\mu g \mathrm{gL}^{-1}\right)$ & Range & Mean ( \pm S.D.) & $\% \mathrm{CV}$ & \\
\hline \multicolumn{5}{|c|}{ Metformin } \\
\hline LC (4) & $3.96-4.12$ & $4.04 \pm 0.090$ & 2.061 & $101.00 \pm 0.028$ \\
\hline IC (8) & $7.95-8.08$ & $8.02 \pm 0.092$ & 1.147 & $100.25 \pm 0.011$ \\
\hline $\mathrm{HC}(12)$ & $11.93-12.17$ & $12.05 \pm 0.170$ & 1.408 & $100.42 \pm 0.035$ \\
\hline \multicolumn{5}{|c|}{ Diclofenac sodium } \\
\hline $\mathrm{LC}(8)$ & $8.02-8.07$ & $8.04 \pm 0.035$ & 0.439 & $100.50 \pm 0.032$ \\
\hline IC (16) & $15.99-16.11$ & $16.05 \pm 0.067$ & 0.415 & $100.31 \pm 0.035$ \\
\hline $\mathrm{HC}(24)$ & $23.89-24.01$ & $23.95 \pm 0.072$ & 0.301 & $99.79 \pm 0.035$ \\
\hline \multicolumn{5}{|c|}{ Flurbiprofen } \\
\hline $\mathrm{LC}(8)$ & $7.77-7.94$ & $7.86 \pm 0.089$ & 1.132 & $98.25 \pm 0.103$ \\
\hline IC (16) & $15.90-16.08$ & $15.99 \pm 0.090$ & 0.564 & $99.93 \pm 0.007$ \\
\hline $\mathrm{HC}(24)$ & $24.00-24.23$ & $24.12 \pm 0.118$ & 0.489 & $100.5 \pm 0.081$ \\
\hline \multicolumn{5}{|c|}{ Ibuprofen } \\
\hline LC (8) & $7.81-8.00$ & $7.91 \pm 0.127$ & 1.602 & $98.88 \pm 0.067$ \\
\hline IC (16) & $15.79-16.10$ & $15.95 \pm 0.206$ & 1.292 & $99.69 \pm 0.035$ \\
\hline $\mathrm{HC}(24)$ & $23.85-24.00$ & $23.93 \pm 0.076$ & 0.319 & $99.71 \pm 0.053$ \\
\hline \multicolumn{5}{|c|}{ Mefenamic acid } \\
\hline $\mathrm{LC}(8)$ & $7.78-7.91$ & $7.85 \pm 0.072$ & 0.922 & $98.13 \pm 0.110$ \\
\hline IC (16) & $15.83-15.90$ & $15.86 \pm 0.051$ & 0.323 & $99.13 \pm 0.095$ \\
\hline $\mathrm{HC}(24)$ & $23.87-24.00$ & $24.03 \pm 0.155$ & 0.646 & $100.13 \pm 0.018$ \\
\hline \multicolumn{5}{|c|}{ Meloxicam } \\
\hline $\mathrm{LC}(8)$ & $7.87-7.98$ & $7.93 \pm 0.091$ & 1.145 & $99.13 \pm 0.053$ \\
\hline IC (16) & $16.00-16.14$ & $16.07 \pm 0.099$ & 0.616 & $100.44 \pm 0.049$ \\
\hline HC (24) & $23.89-24.16$ & $23.98 \pm 0187$ & 0.779 & $99.91 \pm 0.018$ \\
\hline \multicolumn{5}{|c|}{ Tiaprofenic acid } \\
\hline $\mathrm{LC}(8)$ & $7.79-7.97$ & $7.83 \pm 0.114$ & 1.441 & $97.87 \pm 0.085$ \\
\hline IC (16) & $15.84-15.96$ & $15.90 \pm 0.083$ & 0.524 & $99.37 \pm 0.071$ \\
\hline $\mathrm{HC}(24)$ & $23.71-23.89$ & $23.80 \pm 0.095$ & 0.397 & $99.16 \pm 0.141$ \\
\hline
\end{tabular}

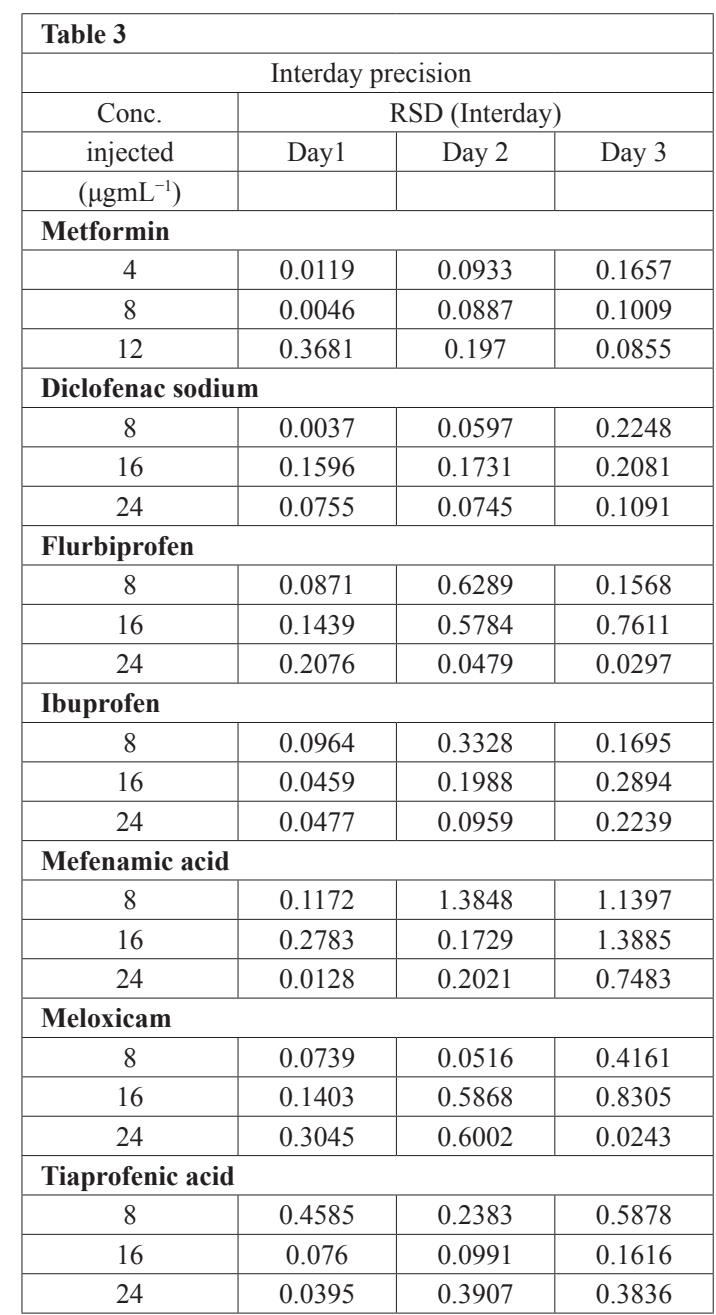

\begin{tabular}{|c|c|c|c|c|c|c|c|c|}
\hline \multicolumn{9}{|l|}{ Table 4} \\
\hline \multicolumn{9}{|c|}{ Interation studies ( $\%$ recovered after interaction in presence of each other) } \\
\hline \multirow{2}{*}{ pH } & Metformin & Diclo. & Metformin & Diclo. & Metformin & Flurbi. & Metformin & Flurbi. \\
\hline & \multicolumn{2}{|c|}{ UV } & \multicolumn{2}{|c|}{ HPLC } & \multicolumn{2}{|c|}{ UV } & \multicolumn{2}{|c|}{ HPLC } \\
\hline 4.000 & 99.019 & 72.38 & 101.21 & 84.38 & 91.41 & 28.22 & 90.08 & 38.05 \\
\hline 6.800 & 95.3 & 36.43 & 33.2 & 99.1 & 92.61 & 69.01 & 99.82 & 79.52 \\
\hline 9.000 & 98.14 & 96.47 & 94.21 & 82.03 & 91.26 & 87.59 & 90.9 & 97.2 \\
\hline \multirow{2}{*}{ pH } & Metformin & Ibuprofen & Metformin & Ibuprofen & Metformin & Mefanem. & Metformin & Mefanem. \\
\hline & \multicolumn{2}{|c|}{ UV } & \multicolumn{2}{|c|}{ HPLC } & \multicolumn{2}{|c|}{ UV } & \multicolumn{2}{|c|}{ HPLC } \\
\hline 4.000 & 95.39 & 99.12 & 106.72 & 99.11 & $\&$ & $\&$ & $\&$ & $\&$ \\
\hline 6.800 & 97.38 & 88.74 & 92.73 & 98.09 & 97.18 & 26.2 & 94.9 & 22.5 \\
\hline 9.000 & 97.58 & 96.28 & 100.3 & 86.29 & 93.07 & 77.93 & 93.5 & 73.53 \\
\hline \multirow{2}{*}{ pH } & Metformin & Meloxicam & Metformin & Meloxicam & Metformin & Tiapro. & Metformin & Tiapro. \\
\hline & \multicolumn{2}{|c|}{ UV } & \multicolumn{2}{|c|}{ HPLC } & \multicolumn{2}{|c|}{ UV } & \multicolumn{2}{|c|}{ HPLC } \\
\hline 4.000 & 91.19 & 45.2 & 92.67 & 42.2 & 97.16 & 1.48 & 98.26 & 3.7 \\
\hline 6.800 & 99.28 & 61.82 & 89.11 & 93.06 & 93.17 & 44.37 & 97.05 & 39.5 \\
\hline 9.000 & 93.07 & 77.92 & 94.05 & 74.6 & 88.86 & 32.98 & 84.5 & 35.4 \\
\hline
\end{tabular}




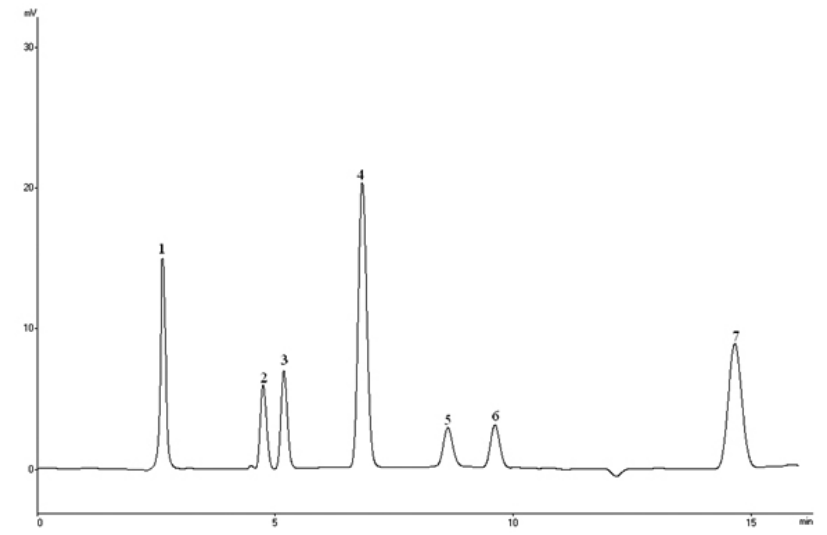

Figure 1: A typical chromatogram showing ${ }^{1}$ Metformin, ${ }^{2}$ flurbiprofen, ${ }^{3}$ ibuprofen, ${ }^{4}$ tiaprofenic acid, ${ }^{5}$ meloxicam, ${ }^{6}$ diclofenac sodium and ${ }^{7}$ Mefenamic acid peaks in pharmaceutical dosage formulations.

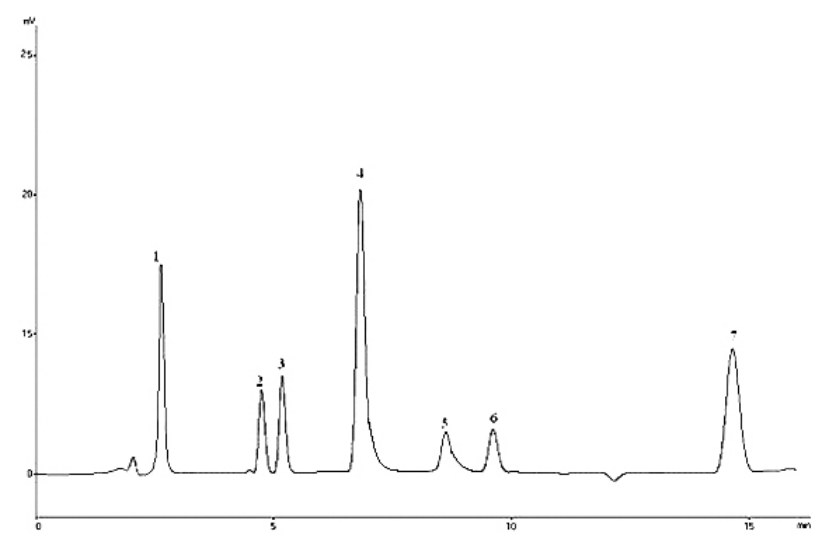

Figure 2: A typical chromatogram showing ${ }^{1}$ Metformin, ${ }^{2}$ flurbiprofen, ${ }^{3}$ ibuprofen, ${ }^{4}$ tiaprofenic acid, ${ }^{5}$ meloxicam, ${ }^{6}$ diclofenac sodium and ${ }^{7} \mathrm{Mefenamic}$ acid peaks in presence of human serum.

\section{REFERENCES}

1. D.J. Abraham, Autocoids, Diagnostics and Drugs from New Biology. J. Wiley and Sons.New Jersey, 2003.

2. R. Guthrie, The Journal of the American Board of Family Practicel American Board of Family Practice. 10, 213 (1997).

3. A.J. Scheen, Clinical pharmacokinetics. 30, 359-371 (1996).

4. M.S. Arayne, N. Sultana, H. Shamhad, and A.Z. Mirza, Medicinal Chemistry Research (2009).

5. K. Chlud, Zeitschrift für Rheumatologie. 35, 377, (1976).

6. P.V. Diwan, M.S. Sastry, and N.V. Satyanarayana, Indian journal of experimental biology. 30, 317 (1992).

7. E. Elvander-Ståhl, A. Melander, and E. Wåhlin-Boll, British Journal of Clinical Pharmacology. 18, 773 (1984).

8. B.L. Kolte, B.B. Raut, A.A. Deo, M.A. Bagool, and D.B. Shinde, Journal of chromatographic science. 42, 70-73 (2004).

9. M.M. Wanjari, A.W. There, M.R. Tajne, C.T. Chopde, and S.N. Umathe, Indian Journal of Pharmaceutical Sciences. 70, 198 (2009).

10. D. Jain, S. Jain, and M. Amin, Journal of chromatographic science. 46, 501-504 (2008).

11. C.L. Cheng and C.H. Chou, Journal of Chromatography B: Biomedical Sciences and Applications. 762, 51-58 (2001).

12. M.S. Arayne, N. Sultana, and M.H. Zuberi, Pakistan journal of pharmaceutical sciences. 19, 231 (2006).

13. S. AbuRuz, J. Millership, and J. McElnay, Journal of Chromatography B. 817, 277-286 (2005).

14. K.H. Yuen and K.K. Peh, Journal of Chromatography B: Biomedical Sciences and Applications. 710, 243-246 (1998).
15. T. Kubala, B. Gambhir, and S.I. Borst, Drug Development and Industrial Pharmacy. 19, 749-757 (1993).

16. N. Sultana, M.S. Arayne, and N. Shafi, Pakistan journal of pharmaceutical sciences. 20, 202 (2007).

17. G. Giagoudakis and S.L. Markantonis, Journal of pharmaceutical and biomedical analysis. 17, 897-901 (1998).

18. O. Kuhlmann, G. Stoldt, H.G. Struck, and G.J. Krauss, Journal of pharmaceutical and biomedical analysis. 17, 1351-1356 (1998).

19. A.P. Argekar and S.J. Shah, Indian drugs. 34, 437-442 (1997).

20. R.J. Sawchuk, J.A. Maloney, L.L. Cartier, R.J. Rackley, K.K.H. Chan, and H.S.L. Lau, Pharmaceutical research. 12, 756-762 (1995).

21. C. Arcelloni, R. Lanzi, S. Pedercini, G. Molteni, I. Fermo, A. Pontiroli, and R. Paroni, Journal of Chromatography B: Biomedical Sciences and Applications. 763, 195-200 (2001).

22. B.W. Berry and F. Jamali, Pharmaceutical research. 5, 123-125 (1988).

23. J. Askholt and F. Nielsen-Kudsk, Acta pharmacologica et toxicologica. 59, 382-386 (2009).

24. K.S. Albert, W.R. Gillespie, A. Raabe, and M. Garry, J Pharm Sci. 73, 1823-5 (1984)

25. S. Ravisankar, M. Vasudevan, M. Gandhimathi, and B. Suresh, Talanta. 46, 1577-1581 (1998).

26. H. Farrar, L. Letzig, and M. Gill, Journal of Chromatography B. 780, 341-348 (2002).

27. E.S. Jung, H.S. Lee, J.K. Rho, and K.I. Kwon, Chromatographia. 37, 618-622 (1993).

28. M.R. Rouini, A. Asadipour, Y.H. Ardakani, and F. Aghdasi, Journal of Chromatography B. 800, 189-192 (2004).

29. T. Hirai, S. Matsumoto, and I. Kishi, Journal of Chromatography B: Biomedical Sciences and Applications. 692, 375-388 (1997).

30. J. Sato, E. Owada, K. Ito, Y. Niida, A. Wakamatsu, and M. Umetsu, Journal of chromatography. Biomedical applications. 493, 239-243 (1989).

31. G. Geisslinger, S. Menzel, and K. Brune, Journal of Chromatography B: Biomedical Sciences and Applications. 675, 77-81 (1996).

32. R. Ferretti, B. Gallinella, F. La Torre, and C. Villani, Journal of Chromatography A. 704, 217-223 (1995).

33. R. Mehvar, F. Jamali, and F.M. Pasutto, Clinical Chemistry. 34, 493 (1988).

34. T. Velpandian, J. Jaiswal, R.K. Bhardwaj, and S.K. Gupta, Journal of Chromatography B: Biomedical Sciences and Applications. 738, 431-436 (2000).

35. J. Joseph-Charles and M. Bertucat, Analytical letters. 32, 2051-2059 (1999).

36. J.W. Bae, M.J. Kim, C.G. Jang, and S.Y. Lee, Journal of Chromatography B. 859, 69-73 (2007)

37. B. Dasandi, H. Saroj, and K.M. Bhat, Journal of pharmaceutical and biomedical analysis. 28, 999-1004 (2002).

38. N.H. Zawilla, M. Abdul-Azim Mohammad, N.M. El Kousy, and S.M. ElMoghazy Aly, Journal of pharmaceutical and biomedical analysis. 32, 1135-1144 (2003).

39. H.Y. Ji, H.W. Lee, Y.H. Kim, D.W. Jeong, and H.S. Lee, Journal of Chromatography B. 826, 214-219 (2005).

40. A.A. Elbary, N. Foda, and M. Elkhateeb, Analytical letters. 34, 1175-1187 (2001).

41. S.S.M. Hassan, W.H. Mahmoud, M.A.F. Elmosallamy, and A.H.M. Othman, Analytica Chimica Acta. 378, 299-311 (1999).

42. M.G. El-Bardicy, S.Z. El-Khateeb, A.K.S. Ahmad, and H.N. Assaad, Spectroscopy letters. 22, 1173-1181 (1989).

43. S. Ashour and R. Kabbani, Analytical letters. 36, 361-370 (2003).

44. B.V. Kamath, K. Shivram, G.P. Oza, and S. Vangani, Analytical letters. 26, 665-674 (1993).

45. E. Dinç, C. Yücesoy, and F. Onur, Journal of pharmaceutical and biomedical analysis. 28, 1091-1100 (2002).

46. M.I. Toral, P. Richter, E. Araya, and S. Fuentes, Analytical letters. 29, 2679-2689 (1996).

47. E.M. Hassan, Journal of pharmaceutical and biomedical analysis. 27, 771-777 (2002).

48. B. Pharmacopoeia, London: HMSO, 483, 1993.

49. S.C. Chow and J. Shao, Statistics in drug research: methodologies and recent developments. CRC Press, (2002).

50. S.C. Chow, Statistical design and analysis of stability studies. Chapman \& Hall, (2007).

51. J.M. Green, Anal. Chem. 68, 305A-309A (1996). 
52. ICH Guideline. Validation of analytical procedures: Text and Methodology Q2 (R1). 2005.

53. M.S. Arayne, N. Sultana, S. Naseem, and A.Z. Mirza, Medicinal Chemistry Research (2009)
54. M.S. Arayne, N. Sultana, S.B.S. Rizvi, and U. Haroon, Medicinal Chemistry Research, 1-15 (2009).

55. I.M. Kenawi, B.N. Barsoum, and M.A. Youssef, Journal of pharmaceutical and biomedical analysis. 37, 655-661 (2005). 